\title{
Compressive Strength of Concrete with Recycled Concrete Aggregate as Coarse Aggregate and Recycled Paving Block Aggregate as Fine Aggregate Partially Substituted by Recycled Brick Aggregate
}

\author{
Idi Priyono ${ }^{1, *}$, Meiske Widyarti ${ }^{2}$ and Erizal $^{3}$ \\ ${ }^{1}$ Graduate Student of Civil and Environmental Engineering, Bogor Agricultural University \\ IPB Dramaga Campus PO. BOX 220 Bogor 16002 (West Java, Indonesia) \\ 2 Department of Civil and Environmental Engineering, Bogor Agricultural University \\ IPB Dramaga Campus PO. BOX 220 Bogor 16002 (West Java, Indonesia) \\ ${ }^{3}$ Department of Civil and Environmental Engineering, Bogor Agricultural University \\ IPB Dramaga Campus PO. BOX 220 Bogor 16002 (West Java, Indonesia) \\ *Corressponding author's email: idipriyono2020[AT]gmail.com
}

\begin{abstract}
An excessive extraction of natural resources for aggregate in concrete mix can caused an environmental degradation. According to Indonesia ministry of industry in 2017, the use of cement is predicted will reach 84,96 million tons, that can affected the use of aggregate for concrete mix are quadruplet to $250-350$ million tons. Opimally, the use of recycled material is green method that can reduce an excessive extraction of natural aggregates and keep an environmental sustain. The aim of this study is to obtain recycled aggregate concrete compressive strength and examine recycled aggregate concrete quality in days 3, 7, 28, 35, and 90 along with a proposal of the use of recycled aggregate concrete as a building construction material. This research used experimental method of SNI 03-2834-2002 the standard of normal concrete mix design for f'c 25 MPa then built five types of concrete mix of REC B, REC C, REC D, REC E, and REC F with every types of concrete has four sample are used for compressive strength test. The fine recycled paving block aggregate (RPA) were used partially to substituted a fine recycled brick aggregate $(\mathrm{RBA})$ at $0 \%, 25 \%, 50 \%, 75 \%$, and $100 \%$ by weigth. The result of this study showed the mixed concrete REC D with RCA 100\%, RPA 50\% and RBA 50\% in 28 days is generate highest compressive strength than other recycle aggregates concrete mixes. Compressive strength at 28 days in a mix codes $R E C B, R E C C, R E C D$, REC E and REC F are 18,12 MPa; 18,36 MPa; 19,35 MPa;16,69 MPa; and 16,39 MPa. The results show that it is feasible to replace a natural aggregate entirely by recycled aggregates. With compressive strength over $17 \mathrm{MPa}$ at 28 days, mix codes REC B, REC C and REC D are recommended to use the recycled aggregate concrete for structure of residential buildings but mix codes $R E C E$ and $R E C F$ aren't recommended and only allowed for non-structural concrete such as separate wall (SNI 8140:2016). Based on SNI 03-0691-1996 about solid brick concrete (paving block), recycle aggregate concrete with mix code of $R E C B, R E C C$, and REC D are able to use on paving block with $B$ quality such as parking lot. While, recycled aggregate concrete with mix code of $R E C E$ and $R E C F$ are able to use on paving block with $C$ and $D$ quality which used for pedestrian, garden and other use.
\end{abstract}

Keywords — compressive strength, natural aggregates, recycled aggregate, SNI 8140:2016, SNI 03-0691-1996

\section{INTRODUCTION}

The use of material of natural resources for concrete industry after year 2010 are reached $8-10$ million tons per year [1]. The use of natural aggregate for concrete are estimated three or four times of cement used. According to Indonesian Ministry of Industry in 2017, the use of cement are predicted reach 84,96 million tons, that makes amount of aggregate use for concrete mix are quadruplet at 250 - 350 million tons. It was impacted the contribution of mining and excavation sector in 2016 are $2.59 \%$, it more lower than year 2015 which are $2.81 \%$ with negative growth of $-0.22 \%$ as a consquence of decreased non-renewable natural resources [2].

In these years, many researcher did study about brick waste [3]. Brick waste can be used as a coarse and fine aggregate. Many literature concur that recycled coarse aggregate from demolish bricks usually could increase concrete porosity, reduce mechanic strength and improve durability, so that for structural purpose, it needs to be careful especially 
when exceed the $30 \%$ of RBA (Recycled Brick Aggregate) rate [4]. For non-structural concrete with compressive strength under $25 \mathrm{MPa}$, a concrete with more higher percentage of RBA as coarse aggreagate then substitute with natural coarse aggregate are generated higher loss of compressive strength with following liniear correlation. The whole substitute could affect the result of compressive strength by $45 \%$ more lower than standard concrete mix [5].

Consolidated RBA as fine aggregate also makes concrete need more water during mix process because of higher water absorbtion [6]. Fully substitute of standard fine aggregate with RBA as fine aggregate are lead to resistant fade in middle-strength concrete with compressive strength $40 \mathrm{MPa}$ which evaluated around 30\% [7]. However, interfacial transition zone between RBA and cement pasta, appearly are more relative cohesive according to morphological observe, it is due to rough surface of recycled aggregate and pozzolanic activity. Pozzolanic has effect which could improving concrete mechanical strength [8].

The use of RCA (Recycled Concrete Aggregate) as coarse aggregate could decrease compressive strength by $40 \%$. The other effect of RCA as coarse aggregate are decreased tensile strength by $24 \%$ and modulus of elasticity by $45 \%$ with a higher long-term deformation[9].

RCA as fine aggregate has higher amount of cement pasta than RCA as coarse aggregate with a consequence of increase water absorbtion and decrease density [10]. The negative effect of RCA as fine aggregate, makes it very limited and even prohibited to use [11]. Because of that makes only few literature studying about RCA as fine aggregate [12]. Substitution of whole RCA as fine aggregate to standard aggregate resulting decreased of compressive strength, tensile strength, and flexural strength by $14 \%, 6 \%$, and $23 \%$ [13].

The recycled aggregate which studied use material from recycle concrete waste, paving block, and red bricks that can be reused for building construction material. The aim of this study is to obtain recycled aggregate concrete compressive strength and to examine recycled aggregate concrete quality in days 3, 7, 28, 35, and 90 along with a proposal of the use of recycled aggregate concrete as a building construction material.

\section{METHODOLOGY}

This study was conducted in Laboratory Material and Structural Strength at Departement of Civil and Environmental Engineering of Bogor Agricultural University, Babakan Village, Dramaga District, Bogor Regency, West Java. It started from February until October 2017. Location of study area is shown in Figure 1.

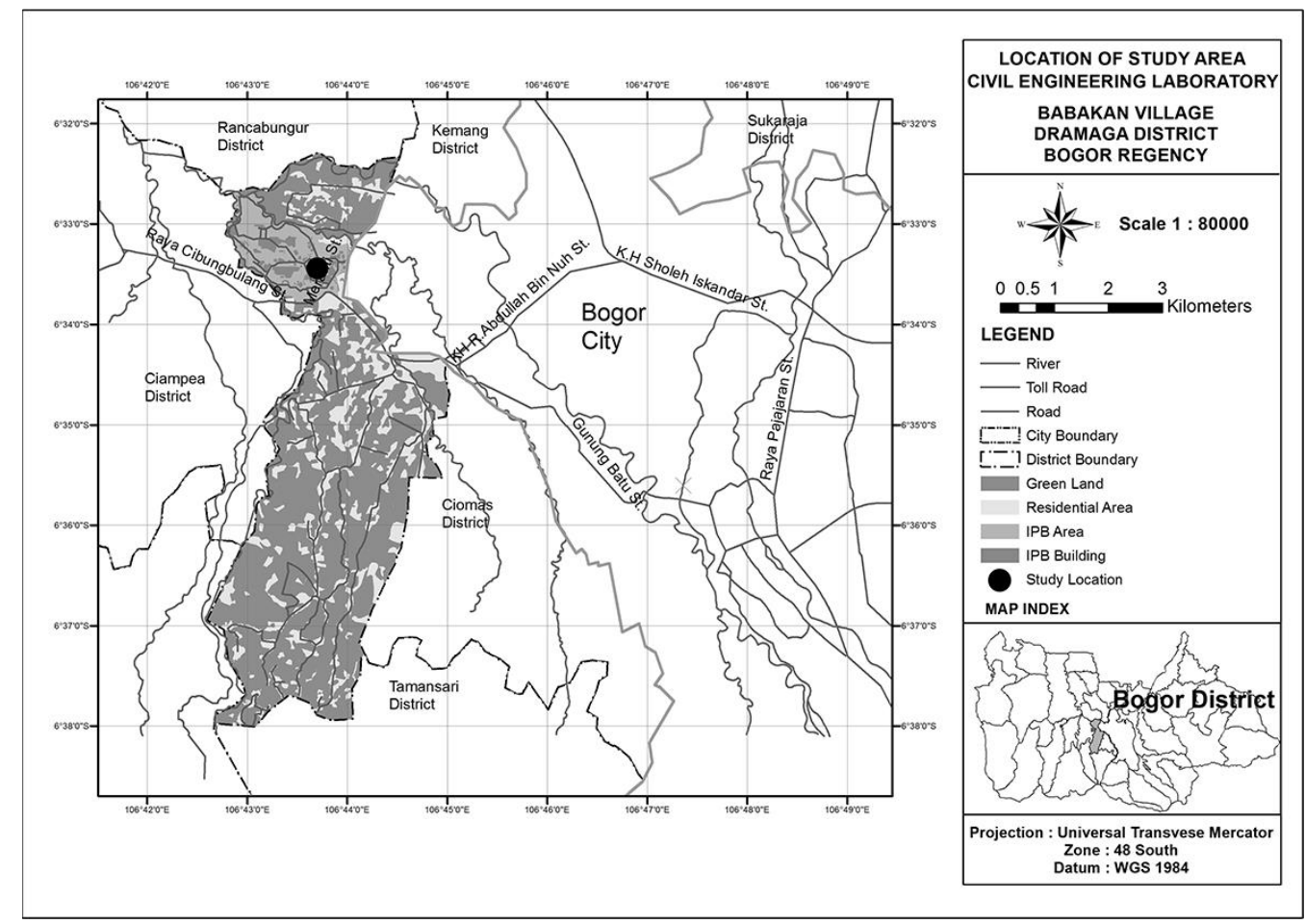

Figure 1. Location of study area

\subsection{Tools and Material}

This study are used tools : concrete molding equipment, slump test equipment, sand filter, bowl, universal testing machine, measuring cup, scales, vibrator, soaking tanks, wet sacks, ovens, concrete mixer, material shrink test machine and hammer test. For material used natural coarse aggregate from stone crusher industry in Cigudeg District and pieces 
of structural concrete from Kebun Raya Residence housing in Bogor city. Natural fine aggregate used pieces of crushed paving block from Pasir Kuda street and pieces of crushed red brick from Kebun Raya Residence housing in Bogor city. The cement used OPC type I with green certificate from Holcim cement industry while the water used from Cihideung river which already cleaned in water treatment at Bogor Agricultural University.

\subsection{Preparation Phase}

Prepare whole tools and material for study in Laboratory of Material and Structural Strength of Departement Civil and Environmental Engineering of Bogor Agricultural University.

\subsection{Material Test}

Material test are used to obtain rough and fine aggregate material quality. List of aggregate and standard test which used are shown in Table 1. Parameters of test result are calculated using Eq. (1), (2), (3), (4), (5), (6), (7), (8), (9), and (10).

Table 1. Type of aggreagate characteristic and standard use test

\begin{tabular}{lcccc}
\hline \multirow{2}{*}{ List of Type } & \multicolumn{2}{c}{ Rough aggregate } & \multicolumn{2}{c}{ Fine aggregate } \\
\cline { 2 - 5 } & \multicolumn{1}{c}{ Standard } & Interval & Standard & Interval \\
\hline Density and absorbtion & SNI 03-1969-2008 & $1.6 \%-3.3 \%$ & SNI 03-1970-2008 & $1.6 \%-3.3 \%$ \\
Volume & SNI 03-1973-1990 & $1.6-1.9 \mathrm{~kg} /$ liter & SNI 03-1973-1990 & $1.4-1.9 \mathrm{~kg} /$ liter \\
Water Content & SNI 03-1971-1990 & $0.5 \%-2 \%$ & SNI 03-1971-1990 & $0.5 \%-5 \%$ \\
Organic Content & - & - & SNI 03-2816-1992 & $<$ No.3 \\
Mud Content & SNI 03-4142-1996 & Max 1\% & SNI 03-4142-1996 & Max 5\% \\
Shrink & SNI 2417-2008 & Max 40\% & - & - \\
Filter analysis & SNI 03-1968-1990 & $6.0-7.1$ & SNI 03-1968-1990 & $1.5-3.8$ \\
\hline
\end{tabular}

$$
\begin{aligned}
\text { Bulk Specific Gravity } & =\frac{B k}{B s s d-B a} \\
S S D & =\frac{B s s d}{B s s d-B a} \\
\text { Apparent Surface Dry } & =\frac{B k}{B k-B a} \\
\text { Absorption } & =\frac{B s s d-B k}{B k} \times 100 \% \\
\text { Aggregate Water Content } & =\frac{W 2-W 5}{W 5} \times 100 \% \\
\text { Mud Content } & =\frac{W 1-W 4}{W 1} \times 100 \% \\
\text { Weight of Loose Aggregate } & =\frac{W 3}{V} \\
\text { Weight of Dense Aggregate } & =\frac{W 6}{V} \\
\text { Voids } & =\frac{[(S x W)-M] x 100}{(\text { SxW })} \\
\text { FM (Fine Modulus) } & =\frac{\sum \text { percentage of cumulative restrain begin with filter } 150 \text { pm. }(0,15 \text { mm) }}{100}
\end{aligned}
$$

Where, $B k$ is weight of drying oven test object, $S S D$ is weight of saturated surface of dryness test material, $B a$ is weight of saturated surface of dryness in water test object, $B$ is pycnometer weight + water, $B T$ is pycnometer weight + test object + water, $W 1$ is weight of aggregate, $W 2$ is weight of test object $+W 3$ is weight of test object in loose condition. W4 is weight of aggregate above filter number 200 and 16, W5 is weight of drying oven test material, W6 is weight of compacted condition of test material, $V$ is cylinder tube volume, $S$ is weight of aggregate type, $M$ is weight of aggregate volume, $F M$ is fine modulus. 


\subsection{Making of Recycled Fine and Rough Aggregate}

The making of fine aggregate such as natural sand, recycled red bricks and recycled paving block sand along with rough aggregate such as crushed natural stone and crushed recycle concrete must be fullfiled the standard requirement. The process of making recycled fine and rough aggregate are shown in Figure 2.

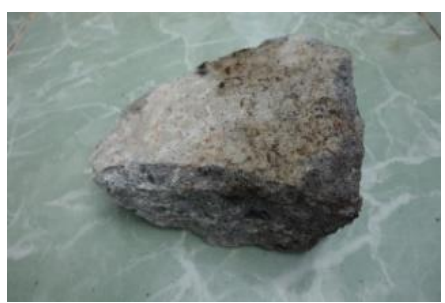

(a) Concrete
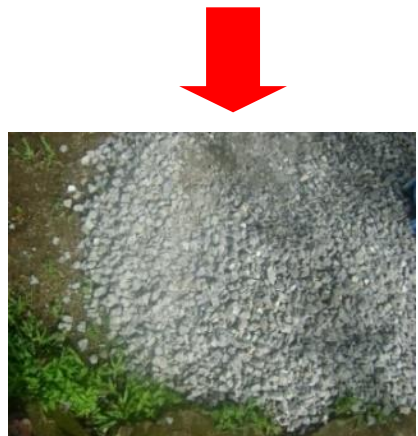

(a) RCA

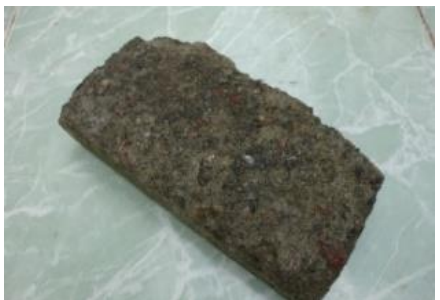

(b) Paving block
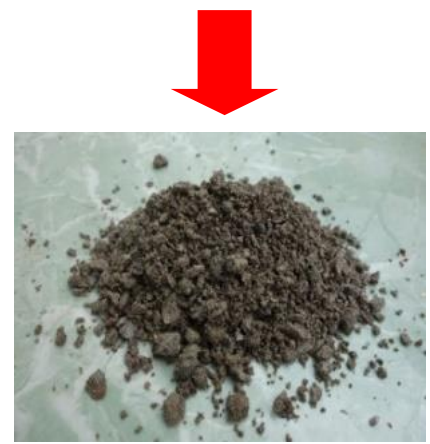

(b) RPA

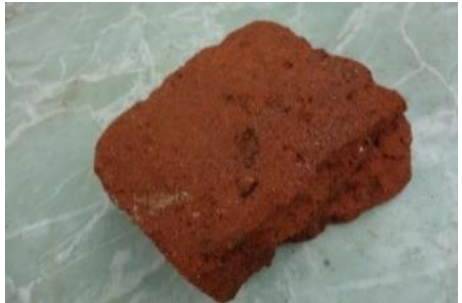

(c) Red brick
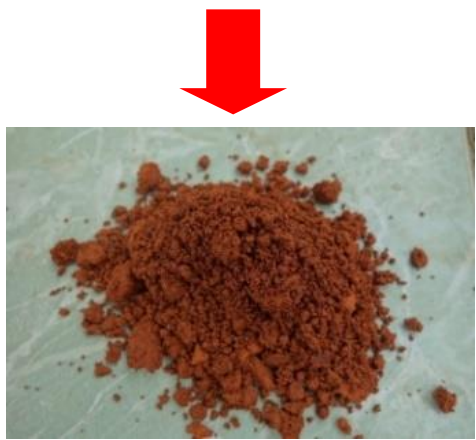

(c) RBA

Figure 2. Process of making recycled concrete aggregate (RCA), recycled paving block aggregate (RPA), recycled brick aggregate (RBA)

\subsection{Making of Test Object}

In this phase, concrete sampling are making with steps: (1) fixing the mix design of concrete; (2) making concrete mix; (3) checking slump value; (4) making cylinder mold test object with diameter of $15 \mathrm{~cm}$ and height of $30 \mathrm{~cm}$, then built four sample with different mix variety. Each test object with different variety mix are shown in Table 2 . Recycle aggreagate concrete mix design is based on SNI 03-2834-2002. It mentioned, in every $1 \mathrm{~m}^{3}$ of standard concrete with f'c $25 \mathrm{MPa}$ is required $262.9 \mathrm{~kg}$ cement, $224.29 \mathrm{~kg}$ water, $705.58 \mathrm{~kg}$ fine aggreagate, and $897.23 \mathrm{~kg}$ coarse aggreagate.

Table 2. The details of sum of cylindrical test object

\begin{tabular}{ccccccc}
\hline \multirow{2}{*}{ No. } & Concrete Mix Code & \multicolumn{5}{c}{ Concrete ages (day) } \\
\cline { 3 - 6 } & & 3 & 7 & 28 & 35 & 90 \\
\hline 1. & NORM A & - & - & - & - & - \\
2. & REC B & 4 & 4 & 4 & 4 & 4 \\
3. & REC C & 4 & 4 & 4 & 4 & 4 \\
4. & REC D & 4 & 4 & 4 & 4 & 4 \\
5. & REC E & 4 & 4 & 4 & 4 & 4 \\
6. & REC F & 4 & 4 & 4 & 4 & 4 \\
\hline & Sum & 20 & 20 & 20 & 20 & 20 \\
\cline { 3 - 6 } & Total & \multicolumn{5}{c}{100} \\
\hline
\end{tabular}

Where, NORM $A$ is a standard concrete with natural aggreagate of NA $100 \%, R E C B$ is concrete with recycle aggreagate of RCA $100 \%$ - RPA $100 \%$ - RBA $0 \%, R E C$ C is concrete with recycle aggreagate of RCA $100 \%$ - RPA $75 \%$ - RBA $25 \%, R E C D$ is concrete with recycle aggreagate of RCA $100 \%$ - RPA 50\% - RBA 50\%, REC E is concrete with recycle aggreagate of RCA $100 \%$ - RPA $25 \%$ - RBA $75 \%, R E C F$ is concrete with recycle aggreagate of RCA $100 \%$ - RPA $0 \%$ - RBA $100 \%$.

\subsection{Treatment of Test Object}

After 24 hours of concrete is molded, the test object must be pull out from the mold and treat the concrete with soak in water until test days is coming. Concrete treatment is used in days 3, 7, 28, 35, and 90 .

\subsection{Tests of Compressive Strength of Test Object}

Concrete compressive strength test is performed in days $3,7,28,35$, and 90 . Concrete compressive strength can 
calculated using Eq. (11) while average concrete compressive strength can obtained using Eq (12).

$$
\begin{array}{ll}
\text { Compressive Strength } & =\frac{P_{\max }}{A} \\
\text { Average Compressive Strength } & =\frac{\sum X_{i}}{n}
\end{array}
$$

Where, $X i$ is compressive strength, $X$ is average compressive strength, $P$ is maximum capacity, $A$ is area of test object, $n$ is sum of test object.

\subsection{Data Analysis}

Stone pieces of coarse aggregate, natural sand of fine aggregate, concrete recycle, paving block recycle and red brick recycle are performed material test. After the result of material test are came out, researcher can continue for making concrete with accordance of SNI 03-2834-2002 the standard of normal concrete mix design for f'c $25 \mathrm{MPa}$. The concrete are built in four test object with cylinder shape of diameter is $15 \mathrm{~cm}$ and height is $30 \mathrm{~cm}$ along with different variety mix and ages. The test object is performed with a curing treatment and continued with compressive strength test at days 3, 7, 28, 35, and 90 to obtain a result of concrete quality. The result of data is analyzed with Lilliefors Method and SPSS Programs. Research flowchart is shown in Figure 3.

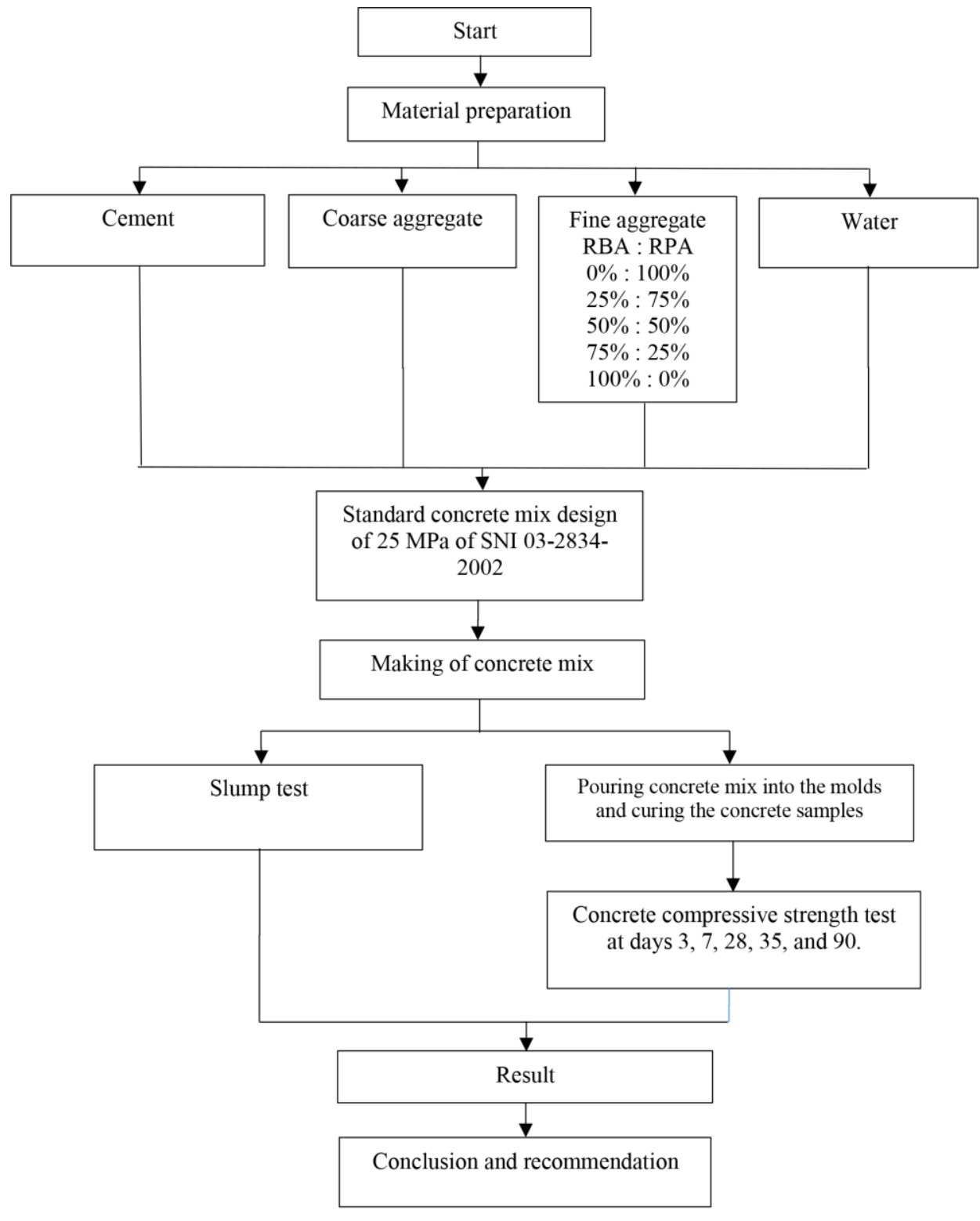

Figure 3. Flowchart research 


\section{RESULT AND DISCUSSION}

\subsection{Concrete Mix Design, Fine and Coarse Aggreagate Test, Slump Test}

Recapitulation of fine and rough aggreagate test result are shown in Table 3 and Table 4. A slump test of each concrete samples are shown in Table 5. Compressive strength of concrete are shown in Table 6.

Table 3. Recapitulation of physical and mechanical test of natural sand

\begin{tabular}{lccc}
\hline Type of Test & Test Result & Standard & Information \\
\hline Mud content & $3.37 \%$ & maximum 5\% & qualify \\
Organic substance contents & $\begin{array}{c}\text { NaOH solution with } \\
\text { transparent color }\end{array}$ & $\begin{array}{c}\text { transparent or } \\
\text { light yellow }\end{array}$ & qualify \\
Bulk specific gravity & 2.08 & - & - \\
Bulk specific gravity (SSD) & 2.18 & - & - \\
Apperent specific grafity & 2.30 & - & - \\
Absorbtion & $4.54 \%$ & - & - \\
Fine modulus & 2.66 & $2.3-3.1$ & qualify \\
Water content & $11.97 \%$ & - & - \\
\hline
\end{tabular}

Table 4. Recapitulation of crushed stone as coarse aggregate test results

\begin{tabular}{lccc}
\hline Type of Test & Test Results & Standard & Information \\
\hline Bulk Specific Gravity & 2.53 & - & - \\
Bulk Specific Gravity (SSD) & 2.56 & - & - \\
Apperent Specific Gravity & 2.59 & - & - \\
Absorbtion & $0.88 \%$ & - & - \\
Water content & $1.45 \%$ & - & - \\
Fine modulus & 5.21 & $5-8$ & qualify \\
Shrink & $17.17 \%$ & Maximum 50\% & qualify \\
\hline
\end{tabular}

Table 5. Slump test results

\begin{tabular}{llcccc}
\hline \multirow{2}{*}{ Mix Code } & \multirow{2}{*}{ Type of Aggregate } & Fine aggregate & \multicolumn{3}{c}{ Slump Value (mm) } \\
\cline { 4 - 6 } & & subtitution & I & II & Average \\
\hline Normal A & natural aggregate & - & - & - & - \\
Rec B & recycle aggregate & brick $0 \%$ & 34 & 36 & 35 \\
Rec C & recycle aggregate & brick 25\% & 30 & 32 & 31 \\
Rec D & recycle aggregate & brick 50\% & 27 & 28 & 27.5 \\
Rec E & recycle aggregate & brick 75\% & 25 & 25 & 25 \\
Rec F & recycle aggregate & brick 100\% & 23 & 20 & 21.5 \\
\hline
\end{tabular}

From Table 5 are seen the effect of subtitution of natural aggregate replaced by recycled aggregate is lowering slump value because of high water absorbtion. However, slump value result is still in designated range of $25-50 \mathrm{~mm}$ except of REC F mix code is $21.5 \mathrm{~mm}$.

Table 6. Compressive strength of concrete

\begin{tabular}{lrrrrr}
\hline \multirow{2}{*}{ Mix codes } & \multicolumn{5}{c}{ Compressive strength (MPa) } \\
\cline { 2 - 6 } & 3 day & 7 day & 28 day & 35 day & 90 day \\
\hline TARGET A & 10.00 & 16.25 & 25.00 & 26.00 & 30.00 \\
REC B & 12.10 & 15.08 & 18.12 & 20.92 & 22.71 \\
REC C & 8.58 & 12.76 & 18.36 & 19.14 & 23.07 \\
REC D & 9.07 & 12.14 & 19.35 & 20.31 & 24.40 \\
REC E & 10.85 & 13.77 & 16.69 & 18.30 & 20.69 \\
REC F & 12.22 & 14.43 & 16.39 & 17.76 & 19.49 \\
\hline
\end{tabular}


The results of standard and recycled concrete compressive strength in days 3, 7, 28, 35 and 90 are shown in Figure 4. Generally, it can be seen that concrete compressive strength is increasing simultaneosuly with a grow concrete ages. In days 3, standard mix concrete compressive strength is $19.43 \mathrm{MPa}$, it more higher than targeted concrete with compressive strength of $10 \mathrm{MPa}$ while the other five type of recycle concrete generate compressive strength under targeted concrete and standard concrete with the biggest value in REC F mix code is $12.22 \mathrm{MPa}$ and the lowest value in REC C is 8.58 $\mathrm{MPa}$. In days 7, standard mix concrete compressive strength is $22.35 \mathrm{MPa}$ while the other five variety of recycle concrete generate compressive strength with the biggest value in REC B mix code is $15.08 \mathrm{MPa}$ and the lowest value in REC D is $12.14 \mathrm{MPa}$. In days 28, standard mix concrete compressive strength is $33.93 \mathrm{MPa}$ while the other five variety of recycle concrete generate compressive strength with the biggest value in REC D mix code is $19.35 \mathrm{MPa}$ and the lowest value in REC F is $16.39 \mathrm{MPa}$. In days 35, standard mix concrete compressive strength is $34.69 \mathrm{MPa}$ while the other five variety of recycle concrete generate compressive strength with the biggest value in REC B mix code is 20.92 $\mathrm{MPa}$ and the lowest value in REC F is $17.76 \mathrm{MPa}$. In days 90 , standard mix concrete compressive strength is $43.11 \mathrm{MPa}$ while the other five variety of recycle concrete generate compressive strength with the biggest value in REC D mix code is $24.40 \mathrm{MPa}$ and the lowest value in REC F is $19.49 \mathrm{MPa}$. Comparison timeline of all recycled aggragate concrete compressive strenght is shown in Figure 4.

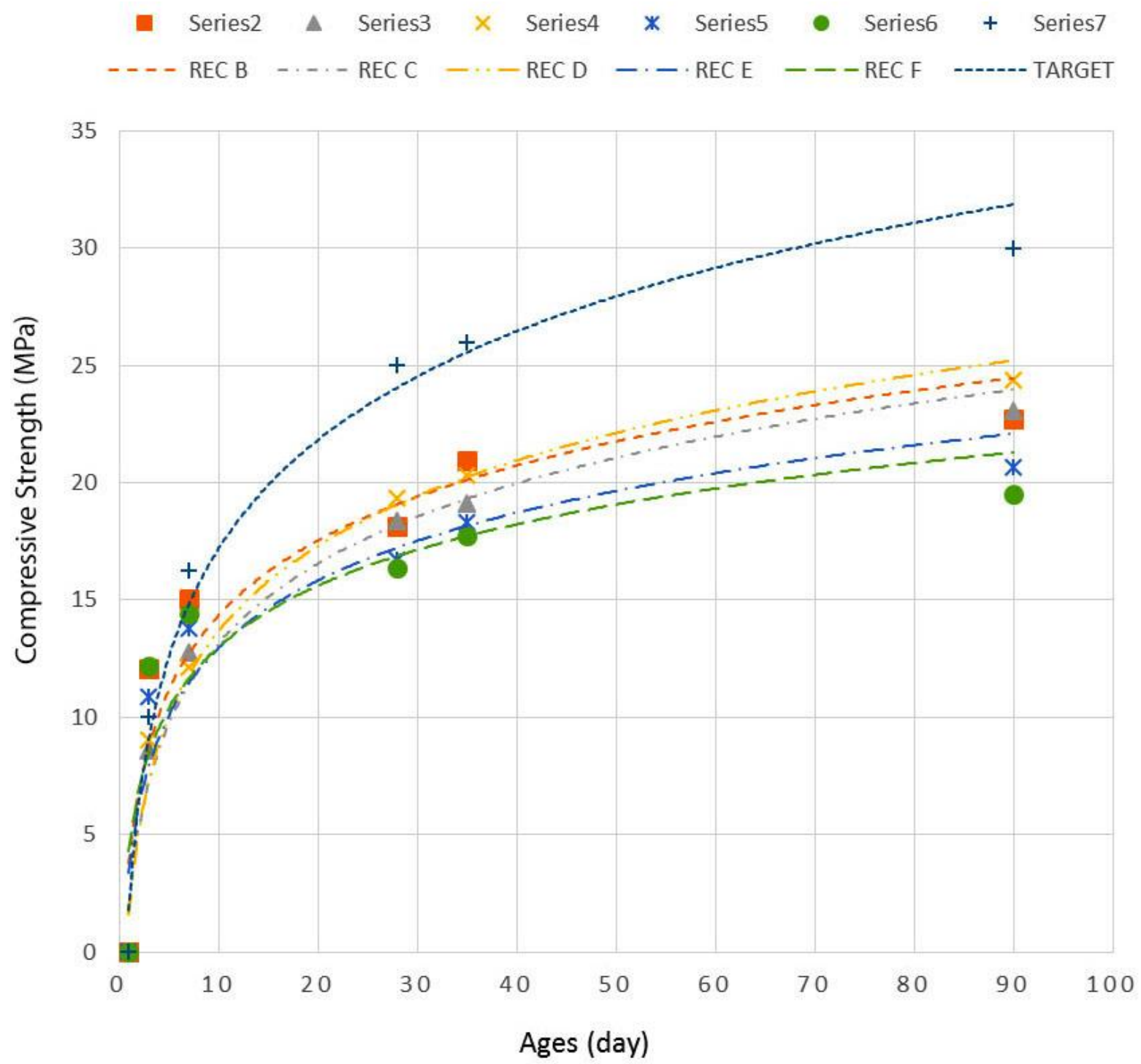

Figure 4. Comparison of timeline all recycled aggregate concrete compressive strength

From the Figure 4 are clearly shows the difference of the development of recycled aggregate concrete compressive strength which are more lower every each days compared to targeted standard concrete. The progress between recycled and standard aggregate concrete in precentage value of targeted compressive strength of $25 \mathrm{MPa}$ in days $3,7,28,35$, and 90 are $63.7 \%-96.68 \%, 54.99 \%-68.87 \%, 48.66 \%-56.97 \%, 50.70 \%-59.71 \%$ and $48.21 \%-59.86$. The good result is seen on mix code of REC D with a composition of $100 \%$ RCA, 50\% RPA, and 50\% RBA in days 28 generate highest 
value of recycled compressive strength of $19.35 \mathrm{MPa}$ and after days 28 is showed good trend than any other recycled aggregate concrete.

\section{CONCLUSION}

1. REC D with a composition of $100 \%$ RCA, 50\% RPA, and 50\% RBA in days 28 generated highest value of recycled compressive strength of $19.35 \mathrm{MPa}$ and after days 28 is showed good trend than any other recycled aggregate concrete.

2. This research results are suggested the use of recycle concrete mix codes REC B, REC C, and REC D with compressive strength over $17 \mathrm{MPa}$ at 28 days, can use as a structural concrete according to SNI 8410-2016 procedural of concrete structures for housing and mix codes REC E and REC F only allowed for non-structural concrete such as separate wall. Based on SNI 03-0691-1996 about quality and test method of solid brick concrete, recycle aggregate concrete with mix code of REC B, REC C, and REC D are able to use as paving block with B quality such as parking lot. While, recycled aggregate concrete with mix code of REC E and REC F are able to use as paving block with C and D quality which used for pedestrian, garden and other use.

\section{REFERENCES}

[1] Mahmood SM, Hashmi SM. An Experimental Investigation on Strength Properties of Concrete Through Full Replacement of Sand by Copper Slag. International Journal of Structural and Civil Engineering Research. Vol. 3, No.4, 2014.

[2] Badan Pusat Statistik Kabupaten Bogor. Produk Domestik Regional Bruto Kabupaten Bogor menurut Kategori 2012-2016. BPS, ID, 2017.

[3] Deng F, He Y, Zhou S, Yu Y, Cheng H, Wu X. Compressive strength prediction of recycled concrete based on deep learning. Construction and Building Materials. vol. 175 pp. 562-569, 2018.

[4] Suárez. J, López F, Pérez CL, Serna P, Serrano MA. Influence of recycled brick aggregates on properties of structural concrete for manufacturing precast prestressed beams. Construction and Building Materials. vol. 149 pp. 507-514, 2017.

[5] De Brito J, Pereira AS, Correia JR. Mechanical behaviour of non-structural concrete made with recycled ceramic aggregates. Cement and Concrete Composites. vol. 27, no. 4 pp. 429-433, 2005.

[6] Vieira T, Alves A, De Brito J, Correia JR, Silva RV. Durability-related performance of concrete containing fine recycled aggregates from crushed bricks and sanitary ware. Materials and Design. vol. 90 pp. 767-776, 2016.

[7] Debieb F, Kenai S. The use of coarse and fine crushed bricks as aggregate in concrete. Construction and Building Materials. vol. 22, no. 5 pp. 886-893. 2008.

[8] Colangelo F, Cioffi R. Mechanical properties and durability of mortar containing fine fraction of demolition wastes produced by selective demolition in South Italy. Composites Part B: Engineering. vol. 22, no. 5 pp. 886-893. 2017.

[9] Sunayana S, Barai SV. Flexural performance and tension-stiffening evaluation of reinforced concrete beam incorporating recycled aggregate and fly ash. Construction and Building Materials. vol. 174, pp. $210-223$. 2018.

[10] Khoury E, Ambrós W, Cazacliu B, Hoffmann C. Heterogeneity of recycled concrete aggregates, an intrinsic variability. Construction and Building Materials. vol. 175, pp. 705-713. 2018.

[11] Pedro D, De Brito J, Evangelista L. Structural concrete with simultaneous incorporation of fine and coarse recycled concrete aggregates: mechanical, durability and long-term properties. Construction and Building Materials. vol. 154, pp. 294-309. 2017.

[12] Oksri-Nelfia L, Mahieux PY, Amiri O, Turcry P, Lux J. Reuse of recycled crushed concrete fines as mineral addition in cementitious materials. Materials and Structures. vol. 49, no. 8 pp. 3239-3251. 2016.

[13] Kumar R, Gurram SCB, Minocha AK. Influence of recycled fine aggregate on microstructure and hardened properties of concrete. Magazine of Concrete Research. vol. 69, no. 24 pp. 1288-1295. 2017. 